\title{
GABRIEL WOLLNER \\ The Third Wave of Theorizing Global Justice. A Review Essay
}

\section{Introduction}

Debates on global justice are flourishing. ${ }^{1}$ In this review article I examine three recent contributions to this debate, which, even though they differ from each other in their overall approach and normative conclusion, exemplify what might be called the third wave of global justice theorizing. ${ }^{2}$ Aaron James's Fairness in Practice, ${ }^{3}$ Mathias Risse's On Global Justice, ${ }^{4}$ and Laura Valentini's Justice in a Globalized World ${ }^{5}$ belong to the third wave of theories of global justice in virtue of a combination of features: They disentangle conceptual and normative disagreements that underpinned debates between cosmopolitans and noncosmopolitans, or statists and globalists; ${ }^{6}$ drawing on their refined conceptual toolkit, they develop both substantive and methodological alternatives to familiar positions; and they take these alternatives as a vantage point for thinking about what justice would require of particular aspects of the international order, sometimes in very practical terms.

My discussion of the third wave proceeds in four steps. First, I shall present the key arguments and most important ideas of each book. I introduce Valentini's coercion framework for thinking about questions of global justice, explain how James thinks of structural equity as a requirement of fairness in international trade, and present Risse's approach of pluralist internationalism and its focus on common ownership of the earth. Second, I shall explain how each contribution exhibits at least some of the features characteristic of the third wave. On the one hand, this section explains why in spite of their differences a common label is

1 I am grateful to Valentin Beck, Julian Culp, Christian Schemmel, Juri Viehoff and Mike Otsuka for very helpful comments and suggestions.

2 Valentini speaks of her own contribution as situated within the third wave of global justice (Laura Valentini, Justice in a Globalized World: A Normative Framework (Oxford: Oxford University Press, 2011), p. 3.) I shall leave open the question of exactly which authors belong to which wave of global justice, but my list of three is by no means exhaustive. Other recent books that might be seen as belonging to the third wave include, among others: Pablo Gilabert, From Global Poverty to Global Equality: a Philosophical Exploration (New York: Oxford University Press, 2012) and Nicole Hassoun, Globalization and Global Justice: Shrinking Distance, Expanding Obligations (Cambridge: Cambridge University Press, 2012).

3 Aaron James, Fairness in Practice: A Social Contract for a Global Economy (New York: Oxford University Press, 2012).

4 Mathias Risse, On Global Justice (Princeton: Princeton University Press, 2012).

5 Valentini (2011).

6 The notions 'statism', 'cosmopolitanism' and 'globalism' are used in different ways by different authors. I shall use cosmopolitanism and globalism interchangeably as the claim that the same principles of distributive justice that apply domestically also apply globally, and statism as the claim that the scope of egalitarian distributive justice is limited to the nation-state. 
appropriate for James, Risse and Valentini. On the other hand, it offers an account of the virtues and strengths of each approach. Third, I present what I believe is a systematic challenge to the third wave of global justice: Each way of covering the middle ground between statism and globalism comes with a particular difficulty, giving rise to what one may call a third wave dilemma. Finally, I conclude by sketching how the third wave is likely to transform the research agenda of international political theorists. Even those developing alternatives to the third wave will have to be measured by the standards it sets.

\section{Main ideas and arguments}

The books by James, Risse and Valentini contribute to contemporary debates about global justice in manifold ways and it would be impossible to do justice to their complexity and richness in a short survey article. At the same time there are one or two key ideas and arguments that are characteristic of each author's approach and will be associated with them as their signature contribution: Valentini develops a coercion framework for global justice, James formulates the idea of structural equity as a requirement of fairness in international trade and Risse comes up with the approach of pluralist internationalism.

a. Global justice and the coercion framework

Valentini's account of global justice comprises two elements: First, a general theory or framework of justice, coercion and freedom; and second, the application of that theory to questions of global justice. Valentini argues that the function of justice is to morally assess instances of coercion; she believes that coercion should be understood more expansively than it hitherto has been, and she advances a conception of "freedom as independence" (p. 156) that draws on elements from both liberal and republican traditions. According to Valentini, thinking about the requirements of global justice within this coercion framework delivers a picture that is distinct from familiar versions of cosmopolitanism and statism, while preserving important insights from both.

Valentini takes the liberal idea that the function of justice is to assess coercion as her starting point, but argues that our understanding of what phenomena are to count as coercive - hence as giving rise to concerns of justice - needs to be widened. Coercion should be understood as encompassing all constraints on individual freedom that stand in need of special justification. We should speak of "interactional coercion" (p. 130) whenever one agent, whether an individual or a group, avoidably and foreseeably places a non-trivial constraint on the freedom of some other agent. And we should speak of "systemic coercion" (p. 137) whenever a system of rules, i.e., the rule-governed behavior of individual or group agents, has the foreseeable and avoidable effect of constraining individual 
freedom. According to Valentini's preferred understanding of freedom, an agent's freedom may be constrained by either reducing the number or quality of options available to that agent, or by reducing the robustness of their options, i.e., by increasing the extent to which the availability of the options depends on the behavior of some other agent. ${ }^{7}$

How does this normative framework apply to questions of global justice? Three implications are particularly important. Firstly, because requirements of justice arise out of a concern for justifying coercion, the content of duties of global justice will depend on how actors in the international arena constrain each other's freedom. In a world of self-contained states, non-interference would be the only requirement of global justice, whereas in a fully integrated world, the coercion framework would deliver cosmopolitan conclusions. Secondly, because a network of different relationships of coercion characterizes the international order in its current form, different principles of justice hold between different actors. On the level of interactional coercion between states, for example, states should respect each other as the primary protectors of their citizens' individual freedom, giving rise to duties of non-interference and a concern for protecting the conditions of effective state sovereignty. ${ }^{8}$ On the level of global systemic coercion, comprising the rules and conventions governing finance and trade, adverse impacts on individual freedom, for example through trade liberalization or financial crises, ought to be minimized, say through enhanced global regulation and fairer bargaining mechanisms within the WTO. And finally, because individuals are responsible for various types of coercion, they are subject to a number of duties of global justice. On the one hand, they share responsibility for global interactional coercion as members of the collective agent of the state. On the other hand, they share responsibility for global systemic coercion as participants in practices such as trade and finance.

\section{b. International trade and structural equity}

Aaron James' key claim is that a fair global economy would have to comply with the requirements of what he calls "structural equity" (p. $131 \mathrm{ff}$.). Relying on his preferred method of constructivist interpretation (p. $25 \mathrm{ff}$. ), ${ }^{9}$ his ambition is to overcome skepticism about both the significance and applicability of fairness concerns to a partially integrated and politically decentralized global economy,

7 Valentini modifies and draws on a notion of robustness familiar from contemporary republican theory as developed by Philip Pettit, Republicanism. A Theory of Freedom and Government (Oxford: Oxford University Press, 1999).

8 For the notion of 'effective sovereignty', see for example: Miriam Ronzoni, 'The Global Order: A Case of Background Injustice? A Practice-Dependent Account', Philosophy \& Public Affairs 37/3 (2009), 229-256.

9 This method is familiar from Aaron James, 'Constructing Justice for Existing Practice: Rawls and the Status Quo', Philosophy \& Public Affairs 33/3 (2005): 281-316. 
and to offer a substantive alternative to both "parochial egalitarianism" (p. 9) and “cosmopolitanism” (p. 11). ${ }^{10}$

Why should fairness matter in the context of international trade? James offers two reasons. First, he argues that requirements of fairness arise because international trade is most appropriately interpreted as a particular social practice, which, because it may be arranged in various alternative ways, raises questions of justifiability. He argues that for trade to be possible at all, there needs to be what he calls an "international market reliance practice" (p. 37). Such a practice solves the basic assurance problems of trading partners (e.g. Will the goods be delivered? Will there be free markets tomorrow?) and depends on an institutional context: International markets depend on non-market institutions that are socially created and which might be structured in alternative ways. As soon as one realizes that such a practice is necessary to enable trade, questions of how the practice would have to be arranged to be acceptable to all participants, i.e. questions of fairness, arise. Second, James argues that the case for trade made by economic theorists, most famously along the lines of trading to comparative advantage, has to rely on a notion of fairness in order to succeed. To justify trade to domestic losers, for example unemployed citizens previously working in manufacturing, free trade will have to be accompanied by compensation and redistribution. The economic case for free trade building on national self-interest and efficiency may succeed only if the institutions that govern the practice of trade are sensitive to concerns of fairness.

What then does fairness require of the global economy? The conception of fairness appropriate for the practice of international trade, for which James uses the name "structural equity," resembles the general complaint model familiar from contractualism in moral philosophy. ${ }^{11}$ It delivers three principles: "The international relative gains principle"(p. $221 \mathrm{ff}$.), "the collective due care principle" (p. 203 ff.), and "the national relative gains principle" (p. 219 ff.). James applies the contractualist model to the structure of the global economy: To find a principle of fairness for the global economy that nobody could reasonably reject, one will have to identify the relevant interests of the global economy's participants, consider the various objections they could raise against all feasible alternatives, and proceed by pair-wise comparison to arrive at those principles that would minimize the greatest individual complaint. First, the "international relative gains principle" states that (subject to some qualifications) the gains of

10 For a fuller summary of James' book, see Gabriel Wollner, 'Review of A. James Fairness in Practice: A Social Contract for a Global Economy', Notre Dame Philosophical Review (2012), ndpr.nd.edu.

11 For the general idea of reasonable rejectability, see Thomas Scanlon, What We Owe to Each Other (Cambridge, Mass.: Belknap Press of Harvard University Press, 1998). 
trade are to be distributed equally between trading nations. James' argument for the benchmark of equality relies on the claims that trading countries are equal in status, that they have symmetrical interest in gaining from trade, and that there are no special prior entitlements to particular gains from trade. Second, trade would be unfair if it augmented national income at the cost of those who lose out domestically. The "due care principle" requires that nobody is left worse off by a free trade regime than he or she would be under autarky. The only way of rendering free trade compatible with due care is through providing social insurance and a safety net. And finally, the "domestic relative gains principle" requires that the fair share of national gains follow a particular distributive pattern domestically: Because citizens in trading countries have equal claims to the gains of trade which are previously un-owned, these gains should, absent special justification, be distributed equally.

\section{c. Pluralist internationalism and common ownership of the earth}

Two terms are central for understanding Mathias Risse's theory of global justice. The notion of "pluralist internationalism" describes his overall framework, within which different principles of justice apply between different groups of individuals, some exclusively within states and some across borders. The notion of "common ownership of the earth" picks up an idea neglected in contemporary theories of global justice and stands for a set of considerations going back to Hugo Grotius, according to which principles of justice governing natural resources apply globally. Within the overall framework of pluralist internationalism, the idea of common ownership plays a particularly important role.

Why is Risse's theory appropriately called pluralist internationalism? Two features explain why. First, Risse's theory is pluralist because it recognizes multiple grounds and principles of justice as relevant to questions of global justice. Grounds of justice are the norm-generating conditions that give rise to a particular (set of) principle(s) of justice governing the allocation of a particular good (the metric or currency of justice) within a particular population (the scope of justice). Risse's version of pluralist internationalism recognizes five different grounds of justice and his book is organized along developing them and drawing out their implications. They include: Membership in a state (chapter 2), common humanity (chapter 4), common ownership of the earth (chapters 5 - 7), membership in the global order (chapter 11), and subjection to the international trading system (chapter 14). Some of these grounds are relational, that is, principles of justice arise in virtue of individuals standing in an essentially practice-mediated relationship with each other (e.g., they are co-citizens of a state). Other grounds are non-relational, that is, they do not presuppose such a relationship (e.g., common humanity). ${ }^{12}$

12 For the distinction between relationalism and non-relationalism, see Andrea Sangiovanni, 'Global Justice, Reciprocity, and the State', Philosophy \& Public Affairs 35/1 (2007), 3-39. 
Second, Risse's theory is internationalist in the sense that it is distinct from both globalism and statism. ${ }^{13}$ Unlike globalists who believe that only one set of principles of justice holds globally between everyone, it recognizes that there are some principles of justice that apply exclusively within the nation state. The state is normatively peculiar because it combines reciprocal cooperation with the exercise of immediate and pervasive coercion, that is, coercion that involves "direct, unmediated access to bodies and assets" (p. 26) and affects the lives of individuals profoundly (chapter 2). And unlike statists, Risse acknowledges that there are principles that apply beyond the nation state, either because the relationship characteristic of the state applies in some weaker version beyond the state, or because there are principles of global scope triggered by non-relational grounds, for example, the ground of common ownership of the earth.

There are two grounds of justice that stand out and should briefly be mentioned: Membership in a state and common ownership of the earth.

First, Risse identifies shared membership in a state as a ground of justice and defends the normative peculiarity of the state. He argues that particularly strong principles of justice, for example the difference principle familiar from Rawls' domestic theory of justice, apply within the statebecause the state is in two respects special: Unlike any other entity, the state is characterized by both legally and politically immediate types of coercion (p. 28) and the state is where particularly dense cooperation governed by norms of reciprocity takes place. Risse draws on both coercion-based and reciprocity-based versions of relationalism to explain why the state is special but allows for the possibility that less immediate forms of coercion (or reciprocity) trigger respectively weaker obligations of justice beyond the state. ${ }^{14}$ Second, Risse employs and develops the idea that humanity collectively owns the earth: His common ownership approach offers a non-relational ground of justice and secularizes an idea prominent in 17th century political philosophy, in particular in the works of Hugo Grotius. Common ownership captures the requirements that arise in virtue of the fact that humanity as a whole relies on the earth, its resources and space. In order to count as just, the distribution of the original resources of the earth will have to give everyone the opportunity to satisfy their basic needs. Beyond revitalizing an important idea that has suffered relative neglect, Risse's account of common ownership offers a new perspective on many issues of global justice, including migration (discussed in chapter 8) and climate change (discussed in chapter 10 ).

13 In Risse's terminology: Globalists are relationists who believe there is only one justice-relevant relationship and it has global scope. Statists believe that there is one justice-relevant relationship and its scope is limited to the nation state. Non-relationists believe that the sole grounds of justice are non-relational.

14 For the coercion-based account, see Michael Blake, 'Distributive Justice, State Coercion, and Autonomy', Philosophy \& Public Affairs 30/3 (2001), 257-296. For the reciprocity-based account see Sangiovanni (2007). 


\section{Protagonists of the third wave?}

Why should the idea of a third wave capture authors as diverse as James, Risse and Valentini? I believe that in spite of their differences and disagreements, there is enough that they have in common to count as protagonists of the third wave of global justice. In particular, it is in virtue of possessing a combination of (at least some of) these five features that they should be seen as belonging to the third wave: First, in thinking about questions of global justice they disentangle conceptual disagreements and shed light on questions of distributive justice more generally; second, drawing on their refined conceptual toolkit, they develop both substantive and methodological alternatives to the familiar positions of statism and globalism; third, they aspire to take requirements of action-guidingness seriously; fourth, their theories of global justice are ambitious and hold the promise of developing into even more general theories; and fifth, they take their theories as a vantage point for thinking about what justice would require, sometimes in very practical terms, of particular aspects of the international order. To be sure, not all protagonists of the third wave put the same emphasis on all of these features and they do so in different ways. But they still belong to the same church.

First, in thinking about questions of global justice protagonists of the third wave introduce important conceptual distinctions and shed light on questions of distributive justice more generally. There are a number of conceptual distinctions and normative possibilities that theorists of domestic justice did not have to recognize because they were indiscernible within the context of the nation state. In the domestic context, for example, a particular scope of justice was accepted as given, different grounds of justice overlapped within that scope, and principles of justice were thus over-determined, or at least present regardless of what ground of justice one endorses. It was only in the context of debates about global justice that questions like the following appeared on the agenda more clearly: Why exactly do principles of justice apply within a particular group of individuals? Given that a particular principle of justice holds in virtue of a particular feature or triggering condition, between whom does this principle apply? Protagonists of the third wave of global justice have brought a number of the underlying distinctions to full fruition: Distinctions between grounds and scope of justice; between different potential grounds of justice; and between justice and other concepts like legitimacy and humanity. Risse's grounds of justice approach illustrates the variety of justice-relevant considerations present at the international level and his discussion of the distribuenda, principles, grounds and scopes of justice (p.5 ff) sheds light on the general structure of theories of justice. Valentini's discussion of how to distinguish between duties of justice and duties of humanity, 
including for example a very interesting argument that duties of humanity may also be coercively enforced (p. $50 \mathrm{ff}$.), also belongs to this category. The third wave protagonists take questions of global justice as an opportunity to improve our understanding of theories of justice in general.

Second, in drawing on their refined conceptual toolkit, James, Risse and Valentini move beyond and develop alternatives to the familiar positions of statism and globalism. On the one hand, they argue against the traditional positions taken within debates of global justice. Valentini turns against cosmopolitanism by arguing that its case relies on unstable intuitions about far-fetched cases (chapter 3$)^{15}$ and she dismisses statism as insufficiently sensitive to the power dynamics and effects of the international system on domestic justice, poverty, etc. (chapter 4). James describes cosmopolitanism as unable to guide real world actors and as requiring an institutional alternative the shape of which we cannot even imagine (chapter 4), and he criticizes statism, or as he puts it, "parochial egalitarianism", for failing to recognize the significance of questions of fairness raised by the global economy (p. 9 ff). On the other hand, protagonists of the third wave provide an alternative to cosmopolitanism and statism by occupying a middle ground: They acknowledge the state and principles of justice within it as special, but they insist that principles of distributive justice also hold internationally. In occupying the middle ground, James, Risse and Valentini pursue different strategies. For Valentini the state is special because of its particular way of exercising coercion, and principles of justice apply internationally because of international interactional and systemic coercion. For Risse the state is special because multiple grounds of justice overlap within the state and because state membership offers the resources for grounding egalitarian principles of justice, and principles of justice apply internationally because of grounds like common humanity, ownership of the earth or membership in the global order. James recognizes the significance of the state through giving it a special role within his theory of fairness in trade, for example the international gains principle allocates gains from trade between states, but he moves beyond statism by spelling out what the practice of trade requires internationally.

Third, protagonists of the third wave take requirements of action-guidingness seriously. They aspire to formulate non-utopian theories capable of offering critical guidance and motivation to real world actors. These aspirations are reflected in both their methodological commitments and normative prescriptions. James, for example, relies on the method of "interpretive constructivism". Comprising the stages of identifying, morally characterizing and critically assessing (p. 28)

15 As Mike Otsuka pointed out to me, some may consider this a great virtue of a view. 
a particular social practice, this approach sits between the approach of "pure interpretivism" (p. 27) of somebody like Michael Walzer and the approach of "pure moralism" (p. 27) of somebody like G.A. Cohen. ${ }^{16}$ Political theory in the constructive interpretation mode, according to James, begins from and addresses actors within the existing political and economic system, taking into account epistemic limitations and uncertainty about the actions of others. A concern for being realistic also leads to caution with regards to normative prescriptions. Valentini takes her observation that statism, in virtue of granting a prominent role to partiality, is more in line with people's sensitivities than cosmopolitanism as support for that view (p. 80). Similarly, she takes the fact of pluralism and reasonable disagreement as a reason for focusing our normative attention on what minimal standards of justice definitely exclude, rather than spelling out what justice ideally requires (p. $176 \mathrm{ff}$.).

Fourth, third wave theories are ambitious and hold the promise of developing into even more general theories. Starting out as theories of global distributive justice, they have the potential to be generalized and applied more widely, delivering an even more systematic and unified approach to questions in international political theory and political morality beyond the state. Valentini's focus on coercion may offer a link between questions of distributive justice and questions of defensive justice, allowing for a discussion of questions of global justice and questions of just war, two sets of questions concerned with the justifiability of coercion, within one normative framework (p. 188). Similarly, putting coercion at the heart of international distributive justice may offer new ways of exploring the links between legitimacy, democracy and justice. Elements of Risse's pluralist internationalism lend themselves to branching out in different ways: The idea of common ownership not only delivers elements of a theory of human rights and normative principles for questions of migration, climate change and obligations to future generations but may easily be developed into a theory of territorial justice, delivering an alternative to the Lockean, Kantian and nationalist positions prominent in the current literature.

And finally, protagonists of the third wave take their respective theory as a vantage point for thinking about what justice would require, sometimes in very practical terms, of particular aspects of the international order and its institutions. Third wave theories of global justice thus not only contribute to closing the gap between political philosophy and public policy but also prove that they take aspirations to empirically informed normative theory seriously. Risse, for example, discusses labor rights (chapter 13), pharmaceuticals (chapter 12)

16 See Michael Walzer, Spheres of Justice. A Defense of Pluralism and Equality (New York: Basic Books, 1983) and G. A. Cohen, Rescuing Justice and Equality (Cambridge, Mass.: Harvard University Press, 2008). 
and accountability within the WTO (chapter 18). James dedicates the final part of his book to a discussion of policy proposals for reforming the institutions of the global economy. He argues that his ideal of structural equity would require a radical revision of the existing intellectual property rights regime (chapter 9) and makes a case, based on the difficulty of justifying risk-imposition, for scaling back international financial markets and introducing capital controls (chapter 10).

\section{How to cover the middle ground? A third wave dilemma}

James, Risse and Valentini provide different ways of exploring the terrain between statism and globalism, and each of them comes with a clear advantage. James explores the practice of international trade and establishes what he believes are the requirements of justice arising from it. The strength of this approach is its depth: To my knowledge there is no treatment of justice or fairness in trade comparable to his. Risse explores a multitude of grounds of justice and thus comes closer to offering a fuller picture of what global justice requires. His strength is comprehensiveness: There is no other account of global justice exploring and linking as many pertinent aspects of the international order in a single book. Valentini builds on the idea that the function of justice is to assess coercion and applies her coercion framework to questions of global scope. Her strength is parsimony: A theory of global justice unfolds from a simple and intuitive idea. I shall argue that the respective advantages come at a cost and that each approach gives rise to an objection or challenge. I shall explain what I take the respective challenge to be and elaborate how seen in conjunction, the different challenges give rise to a dilemma that protagonists of the third wave will have to come to terms with.

\section{a. Does justice only have one function?}

Coercion is at the heart of Valentini's theory of global justice. To figure out who owes what to whom as a matter of justice, we need to find out who coerces whom in what ways. Two claims are central to this account. The first claim is that the function of justice is to assess coercion. This idea is important because it tells us when problems of justice arise, why they arise, and what requirements they give rise to. According to the second claim, we ought to apply a wide instead of a narrow understanding of coercion: Even constraints on freedom that emerge as the unintended aggregate effect of independent individual acts may count as coercive. This idea is important because it allows the coercion theorist to move beyond the focus on state coercion and capture all intuitively justice-relevant phenomena as relevant from the point of view of the coercion framework. I shall argue that Valentini's endorsement of these two claims invites two objections: Her argument for the second claim puts pressure on her first claim and the second claim is independently implausible. She is having coercion do more work than it can do. 
Why should one embrace a wide rather than a narrow understanding of coercion? Valentini's main argument runs along these lines: There are cases where constraints on an individual's freedom give rise to questions of justice without that individual being narrowly or interactionally coerced. The worker who is made redundant by his company experiences a restriction of his freedom that stands in need of justification and raises questions of justice. But because there is nobody who coerces the worker in the narrow sense, a wide understanding of coercion seems appropriate for capturing the normatively salient aspects of the situation (p. 136). Two things should be noted about this argumentative move. First, note that the case of the redundant worker supports the claim that one ought to widen one's understanding of coercion only if we take as given that questions of justice arise exclusively in the context of morally assessing coercion. Assuming, for example, that questions of justice arise where individuals have a profound impact on each other's wellbeing would allow us to discuss the case of the redundant worker in terms of justice without introducing the idea of systemic coercion. The idea that coercion triggers concerns of justice possesses some plausibility, particularly within a liberal tradition, but the claim that it does so exclusively is controversial. Second, note that Valentini's observation about what happens in the case of the redundant worker, i.e. that there are justice-relevant phenomena which the standard view of coercion fails to capture, itself places pressure on the idea of coercion as an exclusive trigger of justice. If one comes across a case that raises questions of justice without there being coercion, modifying one's understanding of coercion such that coercion gets better at tracking questions of justice is only one of the available options. It would be equally plausible to drop the idea that there can be questions of justice only where there is coercion. At least, this avenue would have to be closed off for Valentini's argumentative strategy to succeed, i.e., for the case of the redundant worker to support the wide understanding of coercion crucial to the overall framework.

But maybe Valentini's understanding of wide systemic coercion is independently plausible after all? Here is a reason to be skeptical: Even though coercion is a contested concept, its core is about a particular phenomenon involving a particular wrong. The coercer undermines the autonomy of his victim by subjecting her will to his own, by replacing the victim's ends with his own. ${ }^{17}$ Coercion is generally thought to require that the coercer intends the consequences of his acts. The mere aggregate effect of many non-intentional acts is not coercive because there is nobody who intends these effects. There are many instances where the consequences of some individual's action constrain somebody else's freedom,

17 For seminal contributions to the debate on coercion, see for example Robert Nozick, 'Coercion', in Suppes, Morgenbesser, White (eds.), Philosophy, Science and Method: Essays in Honor of Ernest Nagel (New York: St Martin's, 1969) and Alan Wertheimer, Coercion (Princeton: Princeton University Press, 1987). 
but it would be a stretch to say that these are instances of coercion. Being laid off by her current employer may constrain the redundant worker's freedom in ways that require justification and she will be wronged if no such justification is forthcoming. But why insist that she is coerced? There are different concepts for capturing these other phenomena and the wrongs that they involve. There are constraints on freedom that are not coercive. And there are non-coercive ways of impacting others that stand in need of special justification. These nuances should not be given up. Valentini assumes a tight link between justice and coercion. But insisting that there can be questions of justice only where there is coercion may push coercion beyond its breaking point. Loosening the link between coercion and justice would leave her framework more fragmented but also more plausible.

\section{b. Should trade really be treated separately?}

James focuses on the normative requirements that arise from the practice of international trade and leaves independent considerations of justice aside. Treating the question of trade in isolation from, say, domestic social justice, allows James to explore one ground of justice in great depth. At the same time his strategy comes at a considerable cost. I believe that James' approach generates implausible principles of justice in trade. I will present a brief argument against both his "domestic relative gains principle" and his "collective due care principle", and argue that the nature of his overall approach accounts for the shortcomings of these principles. ${ }^{18}$

James' "domestic relative gains principle" requires that the gains from trade be distributed equally between individuals within each trading nation. But what looks like a plausible egalitarian principle may have very odd implications. The gains from trade only account for part of the overall economic benefits produced within an economy. But why then should the distributive pattern of that particular share matter rather than the overall distributive pattern? Against the background of a Rawlsian theory of distributive justice this question takes a particular form: Why should the gains of trade benefit everyone equally instead of maximally benefitting those who are least well off overall? The idea that the gains from trade should be distributed such that trade does not upset domestic principles of justice seems to offer an important alternative to James' preferred principles. Imagine a case where within one country there is a choice between distributing the gains from trade either such that they benefit the rich and the poor equally, or such that they benefit the poor, narrowing the gap between rich and poor. James' "domestic relative gains principle" would pick out the former option. Egalitarian principles

18 This criticism draws on Mathias Risse and Gabriel Wollner, 'Critical Notice of Aaron James ` Fairness in Practice', Canadian Journal of Philosophy, forthcoming. 
of domestic social justice would pick out the latter option. It is far from clear that James' choice would be the right one.

A similar objection may be raised against James' "collective due care principle". James argues that nobody should be worse off as a consequence of international trade than he or she would be in a closed society. But again the question arises whether an apparently plausible principle manages to convince once its implications for the domestic context are fully spelled out. To be sure, there are cases where the losers of trade liberalization should be compensated, for example through social insurance and other welfare state provisions. The low-skilled worker who loses her job as a consequence of international trade in manufactured goods should not be left worse off than she would be without that trade taking place. But what about cases where trade liberalization would create some losers among those who are very well-off within domestic society while significantly improving the situation of the less-advantaged? Is it really plausible to think that the generally worse-off beneficiaries of trade liberalization owe compensation to the generally better-off losers of trade liberalization? And is it plausible to think that a particular case of trade liberalization that dramatically improves the situation of the domestically worst-off would be impermissible in case it was for some reason impossible to compensate the rich losers? The answer to both of these question seems to be no.

Where does James go wrong? I believe that James makes two related mistakes. First, the problem arises because he treats trade entirely in separation from the wider economic structure within which it is situated. Why see trade as an entirely separate unit of analysis? Why not look at the economic structure, whether domestically or globally, as a whole? It is not clear that James has convincing answers to these questions. Secondly, James does not take seriously enough the possibility that distributing the gains from trade is merely a function of how to distribute the burdens and benefits of overall economic activity. More general requirements of social justice may after all turn out to provide the correct standards of fairness in trade.

\section{c. How to rank competing grounds and principles?}

Risse's pluralist internationalism recognizes a number of grounds of justice and principles associated with them. While this approach captures the variety of normative considerations at play on the international level, it also invites a dual objection about the link, connection, or coherency of the various grounds. It is very difficult to reconcile competing grounds and principles of justice, and pluralist theories of justice, including Risse's, have a hard time offering a unifying vantage point of justice from which to adjudicate between them. 
First, there is a question that any pluralist theory will have to face and that is notoriously difficult to answer: How should the various different principles of justice be combined in cases of conflict? There are cases where due to scarce resources or other limitations, relevant actors cannot live up to all requirements of justice that apply to them. Different grounds of justice are nested or embedded within each other, for example, on the level of the state, and it is not clear how states ought to prioritize the various demands of justice that they face. Pluralists have to decide between two basic options. They may either admit that different principles will have to be intuitively balanced in each case of conflict or they may come up with a systematic priority ranking of principles. Risse decides against the first option and there may be good reasons to do so. The costs of intuitive balancing in particular cases might be too high, especially for a theory of justice concerned with offering guidance to real world actors. But Risse's preferred second option has its problems too. The first problem is that rankings of principles may have implausible implications. On Risse's proposed ranking, the state's obligation to secure an adequate scheme of basic liberties at home takes priority over securing basic human rights abroad (p. 331). Here is a case where this ranking appears problematic: Assume that the contributions of Stalinist Russia were indispensable to the Allies' success in winning World War 2 and securing the very basic human rights of millions of people in Europe, while the only way of enabling the Russian war effort was through a domestic regime that failed to realize adequate basic liberties. It is not clear that by failing to secure adequate basic liberties at home to protect human rights abroad Russia would have acted wrongly. The second problem is that unless the ranking itself follows from a deeper theory or more general vantage point of justice, it will appear to some extent arbitrary and reflect considered judgments easily challenged on grounds of individual cases. As I shall point out next, a theory of justice as pluralist as Risse's may have a hard time coming up with such a principled vantage point or deeper theory of justice.

Given the variety of concerns he identifies, ranging from an account of human rights to a theory of accountability within the WTO, this question appears particularly important. Risse argues that a "theory of justice explains why certain individuals have particularly stringent claims to certain relative or absolute shares, quantities or amounts of something” (p. 4). Unfortunately, it is not clear that this account successfully delineates the domain of justice. Compare the claims that the victims of an earthquake have against a rich neighboring country to the claims that poor citizens of that rich neighboring country have against their own state. If the claims of the victims are treated as non-justice claims, it seems that non-justice claims may be just as stringent, or even more stringent than justice claims. But if to avoid that implication the 
claims of the victims are treated as justice claims, then the line between duties of justice and duties of humanity or beneficence becomes very blurry indeed. The notion of "shares, quantities or amounts" does not seem to settle the question either. Not all grounds and principles that Risse discusses as issues of justice are straightforwardly concerned with the distribution of shares or amounts of some distribuenda. And this is where the deeper worry comes in again: Without a proper account of what exactly turns a normative concern into a concern of justice, one might be unable to formulate an account or vantage point of justice from which to adjudicate between different grounds and principles in cases of conflict. Lack of a unifying account of justice may be the downside of Risse's pluralism.

\section{d. A tension and its significance}

I believe that these particular questions for Valentini, James and Risse are indicative of a systematic challenge that proponents of the third wave will have to come to terms with. I shall recap each of the challenges, sketch a more systematic tension arising from them, and explain how the tension or dilemma matters for the overall argument between the third wave and potential alternatives to it.

Let me offer a diagnosis of the more general issues underpinning the challenges raised against Valentini, James and Risse. I have argued that Valentini's defence of wide coercion overstretches the boundaries of the concept and succeeds only if we presuppose that the sole point and purpose of justice is to morally assess coercion, an assumption that her own examples threaten to undermine. The weakness of her approach seems to be this: It is implausible to reduce all concerns of justice to a concern about coercion. The strategy of capturing everything that matters from the point of view of justice within the coercion framework fails, presumably because coercion, even though it may be a sufficient ground of justice, is not necessary to triggering a concern for justice. James faces a different problem. His principles of justice for trade appear implausible once one recognizes that trade is part of a wider practice, namely the entire domestic and international economic structure. It is not clear why burdens and benefits generated by trade should be allocated according to some independent principle, rather than being governed by more general principles of justice. The problem of James' approach seems to be that by thinking about one ground of justice alone, one risks arriving at the wrong principles for that particular ground. Risse's version of pluralist internationalism, as I have argued, lacks a convincing way of adjudicating between different grounds and principles of justice. It is not clear how actors like the state, facing competing demands of justice, should rank their different obligations. Combined with the observation that there is no clear explanation of what exactly turns a normative consideration into a ground of justice, this challenge points to the difficulty that 
any genuinely pluralist theory will have in formulating a coherent and unifying vantage point of justice.

I believe that there is a dilemma or at least tension arising from the challenges put to Valentini, James and Risse. There are different ways of covering the middle ground between statism and globalism, different approaches to developing a position within the third wave of global justice. The first option is to take one ground of justice accepted by the statist as a starting point and to argue that some version of that ground extends beyond the state. The second option is to identify multiple grounds and argue that while some grounds apply within the context of the state, other grounds trigger a concern for justice internationally. Here is the dilemma: Anyone pursuing the first option will face a variant of the challenge to Valentini. Is it really possible to subsume all justice relevant phenomena under one ground? And anyone pursuing the second option will encounter the problems facing James and Risse: How do we go about determining what one ground of justice requires, let alone figuring out the overall justice obligations of one particular actor, given the fact that different grounds are nested within each other and that the obligations that they give rise will come into conflict with each other? These, I believe, are two very difficult questions at least one of which protagonists of the third wave will have to answer.

But what is the significance of this observation? Advocates of the third wave point out that cosmopolitanism and statism face systematic challenges: As argued by Risse, James and Valentini, there are questions that statists find notoriously hard to answer and there are questions that globalists find notoriously hard to answer. Its ability to overcome these challenges and avoid the associated questions accounts for the appeal of the third wave. But if my arguments are sound, the third wave has its challenges too. And within the overall debate between the third wave and potential alternatives to it, it is the difficulty of answering these questions that advocates of alternative views may have to their advantage. Whatever else may be said against the statist and the globalist, their theories do not face the difficulties that come with convincingly covering the middle ground.

\section{Beyond the third wave}

The third wave authors deliver state-of-the-art theories of global justice and it seems that there are three natural ways of responding to them. One may become a disciple and choose to work within, develop and refine the respective theory, one may become an internal critic and rely on the respective approach to arrive at different conclusions, or one may choose to become a more radical critic, skeptical about the project of the third wave and developing genuine alternatives to it. Let me conclude by making some brief suggestions about what might be involved in each of these responses. 
Those who are generally sympathetic to the approaches of James, Risse and Valentini may focus on issues currently not fully developed within their favored theory. Those keen on refining and developing Valentini's coercion framework may focus on questions of responsibility, including: How exactly is a group agent's responsibility for a particular instance of interactional coercion transmitted to individuals? What exactly is an individual's responsibility for systemic coercion a function of? Valentini's answers to these questions (p. $146 \mathrm{ff}$.) do not yet fully convince. Even though capturing a plausible idea, for example that "one's degree of responsibility will depend on the particular position one occupies within the system" (p. 152), her account remains unclear on how exactly individuals come to share responsibility for systemic effects.

Those who believe that James' notion of structural equity appropriately captures the requirements of fairness in trade may think about how to respond to the problem that his idea of autarky gives rise to. The notion of autarky is central to James' overall argument: He believes that if states could obtain certain gains without trade, they can legitimately keep these gains. Only those economic gains realized through interaction and trade are subject to the requirements of structural equity. But on any plausible reading of the history of international trade, what states can produce in isolation is itself a function of past interactions. ${ }^{19}$ What is the special significance of autarky and how do we make sense of the idea in light of facts about the history of international trade? This is a question that somebody working within James' framework would have to come to terms with.

Those relying on Risse's approach of international pluralism could focus on two sets of issues that concern the notion of a ground of justice. They may work on the normative micro-mechanics that underlie each ground of justice, for example: If it is immediacy that singles out state coercion as special, what is so special about immediacy? Or they may explore the idea of a ground of justice more generally, for example: How do we individuate different grounds of justice, when exactly is a set of considerations sufficiently unified to count as one ground of justice, and under what circumstances should we distinguish between different grounds, say international trade and the international economic order?

Internal critics may rely on the approaches of James, Risse and Valentini to arrive at different normative conclusions, for example conclusions that are more traditionally statist or globalist. Here are two suggestions. First, progressive internal critics may draw on Risse's notion of common ownership of the earth and argue that it has more egalitarian implications than Risse allows. Once one agrees that individuals have symmetric claims to resources and space, why should a sufficientarian rather than an egalitarian principle capture the requirements of

19 For a fuller development of that point, see Thomas Pogge, 'World Poverty and Human Rights', Ethics \& International Affairs 19/1 (2005), 1-7, and Risse and Wollner (forthcoming). 
common ownership? A similar strategy may be pursued with the idea of common humanity. There are grounds of justice that may deliver egalitarian principles with a global scope. Second, conservative internal critics may argue that fairness in trade only warrants principles less egalitarian than the ones that James arrives at. Even if James' overall characterization of the practice of trade is correct, the idea of contributory fairness may turn out to be more plausible than James admits. Instead of distributing the gains from trade equally between trading nations, there could be a case to be made that trading partners should be compensated in proportion to what they do for others, for example in proportion to the extent to which they benefit others by enabling them to produce to comparative advantage. The principles governing the practice of international trade may be less egalitarian than James believes.

What about the response of a more radical critic, say, a non-relational cosmopolitan who does not believe that principles of justice arise within a particular practice or relationship and denies that justice depends on a triggering condition like coercion? I believe that her most promising argumentative strategy would be this: The non-relational critic should show that whatever consideration is introduced as a ground of justice, that consideration is irrelevant to the emergence of the normative principle in question. It has been argued, for example, that coercion is neither necessary nor sufficient for triggering egalitarian distributive demands, ${ }^{20}$ and similar arguments might be put forward against other grounds of justice. If, after having exhausted and dismissed all candidate relational grounds, one is still convinced that the respective principle of justice applies, it is reasonable to conclude that it applies irrespective of the relationship or practice. If upon closer scrutiny none of the conditions that characterize cooperation within the state succeed in grounding domestic principles of justice, and we still believe that principles of justice apply domestically, these must apply in virtue of something other than the practice of living in a state. It is not clear that this argumentative strategy will succeed, but it seems the best shot for those skeptical about the overall project of the third wave. There is one additional caveat. Whatever alternative the skeptic chooses to develop, she will have to live up to the benchmarks set by the third wave and formulate a theory that is similarly sophisticated, nuanced, and relevant. The standards are higher than ever.

20 See for example: Simon Caney, 'Humanity, Associations, and Global Justice', The Monist 94/4 (2011), 506-534; Andrea Sangiovanni, 'The Irrelevance of Coercion, Imposition, and Framing to Distributive Justice', Philosophy \& Public Affairs 40/2 (2012), 79-110; and Gabriel Wollner, 'Equality and the Significance of Coercion', Journal of Social Philosophy 42/4 (2011), 363-381. 
Dr. Gabriel Wollner

Department of Philosophy, Logic

and Scientific Method,

London School of Economics

and Political Science

email: G.Wollner@/se.ac.uk

the global justicenetwork 